\title{
CAMINHANDO ENTRE GIGANTES: A INSERÇÃO INTERNACIONAL DOS TIGRES ASIÁTICOS E DOS PAÍSES DA ASEAN ${ }^{1}$
}

\author{
Bruno Magno* \\ Bruno Gomes Guimarães ${ }^{* * *}$ \\ Rômulo Barizon Pitt ${ }^{* * *+}$ \\ Athos Munhoz \\ Raoni Fonseca Duarte
}

Resumo

$\mathrm{O}$ artigo procura responder como os quatro Tigres Asiáticos e os países membros da ASEAN estruturaram as suas relações exteriores para sobreviver entre as grandes potências que têm influência sobre a correspondente região asiática. Primeiramente, analisa-se o impacto da industrialização dos Tigres sobre os realinhamentos regionais e nas alianças internacionais. Logo após, é examinado o papel diplomático e econômico da ASEAN desde o fim da Segunda Guerra da Indochina e também as modificações ocorridas com a adesão

\footnotetext{
1 A pesquisa foi realizada com o apoio do UFRGS Model United Nations 2011. " Graduando do curso de Relações Internacionais na UFRGS e pesquisador do Instituto Sul-Americano de Política e Estratégia (ISAPE).

** Graduando do curso de Relações Internacionais da UFRGS e Secretário-Geral do UFRGSMUN 2011.

Graduando do curso de Relações Internacionais na UFRGS e pesquisador do ISAPE.

Graduando do curso de Relações Internacionais na UFRGS e pesquisador do ISAPE.

Graduando do curso de Relações Internacionais na UFRGS.
} 
126 | InterAção

de novos membros à organização. Por fim, responde-se a questão e expõem-se perspectivas àqueles países.

Palavras-chave: Tigres Asiáticos, ASEAN, inserção internacional.

\section{Abstract}

The article tries to answer how the four Asian Tigers and ASEAN member countries have structured their foreign affairs for surviving between the great powers that have influence over the corresponding Asian region. Firstly, it's analyzed the impact of the industrialization of the Tigers over regional realignments and international alliances. After that, it's examined ASEAN's diplomatic and economic role since the end of the Second Indochina War and also the modifications that occurred with the entrance of new members in the organization. Finally, the question is answered and perspectives for those countries are exposed.

Keywords: Asian Tigers, ASEAN, international insertion.

\section{INTRODUÇÃO}

O presente artigo tem como objetivo elucidar a questão de como os chamados "Tigres Asiáticos" - quais sejam: Cingapura, Coreia do Sul, Hong Kong e República da China (Taiwan) - e a Associação das Nações do Sudeste Asiático (ASEAN) estruturaram a sua política internacional para poder sobreviver entre as grandes 
potências com forte influência na região e como eles poderiam se comportar no futuro, buscando tendências para tal. Os países compreendidos como grandes potências influentes, os "gigantes", são, nomeadamente, a República Popular da China (RPC), o Japão, a União Soviética/Rússia, os Estados Unidos (EUA) e em menor grau a Índia. Para isso, dividir-se-á o trabalho em dois momentos, um específico sobre os quatro Tigres e outro sobre os países da ASEAN. No primeiro momento, serão verificados os realinhamentos regionais decorrentes da industrialização dos Tigres, bem como o seu impacto nas grandes alianças internacionais. Logo após, será analisado o papel diplomático e econômico da ASEAN desde o fim da Segunda Guerra da Indochina e também da adesão de novos membros à organização. Por fim, esses dois pontos serão comparados visando a responder a questão inicial e as perspectivas para o futuro são apontadas.

\section{0 impacto internacional da industrialização dos quatro Tigres Asiáticos}

A região do Leste Asiático esteve sob o domínio direto ou indireto do Império Japonês do início do século XX até o final da $2^{\text {a }}$ Guerra Mundial. Com a derrota do Japão nessa guerra, os Estados Unidos assumiram esse papel de aglutinador da região. Assim percebe-se o grande peso que essas duas grandes potências - Japão e Estados Unidos - tiveram (e têm) na região ao longo do período abarcado pelo trabalho.

Antes da industrialização dos quatro Tigres Asiáticos propriamente dita, ocorreu o chamado "milagre" japonês a partir do final dos anos 50, ganhando força expressiva durante os anos 60. Nesse 
período, o país cresceu continuamente a taxas bastante significativas e pôde reestruturar a sua economia, reinserindo-se com força na dinâmica do comércio mundial, sendo os Estados Unidos o parceiro primordial. O formidável desempenho econômico do Japão foi possibilitado pelo seu sistema de subcontratações inigualável até então, no qual as empresas cooperam entre elas para minimizar a competição entre pequenas e grandes empresas no mercado de trabalho. Uma vez esgotada a capacidade de expansão do sistema dentro do próprio país - os ganhos de produtividade já não eram mais suficientes para contrapor a tendência de queda da taxa de lucro - , ele se difundiu transnacionalmente, notadamente para os Tigres Asiáticos, a fim de desfrutar da abundante e competitiva mão de obra daqueles países (ARRIGHI, 1997).

Convém ressaltar que a expansão externa das firmas japonesas foi antes fruto da necessidade do que da escolha, necessidades essas oriundas das crises do petróleo, da insustentabilidade do estado de bem-estar social nos EUA e do fim do padrão-ouro durante os anos 70. Assim sendo, uma nova divisão regional (até mesmo internacional) da produção e do trabalho foi se estabelecendo na região (VIZENTINI \& RODRIGUES, 2000). As multinacionais japonesas se viram, então, dispostas a fazer concessões às exigências dos países que as receberiam no sentido de industrializá-los. Além disso, era do próprio interesse nipônico o estabelecimento, sob sua liderança, de pontos industriais estratégicos para o fornecimento de insumos e de componentes para as suas indústrias, a fim de diminuir a sua dependência dos Estados Unidos. Todas essas transformações alteraram de forma considerável a logística e a distribuição da produção industrial 
InterAção | 129

na região a partir da fragmentação da mesma entre diferentes centros industriais.

Desta feita, as tecnologias intensivas em mão de obra e de valor agregado mais baixo do Japão foram transferidas para os Tigres, enquanto que o polo dinamizador japonês se especializaria no desenvolvimento de tecnologia de ponta. $\mathrm{Na}$ década seguinte, seria a vez de os Tigres repassarem essas tecnologias para outros países, principalmente aos da ASEAN e à China, com o objetivo de se focarem também em técnicas mais avançadas de manufatura, bem como no setor de serviços (no financeiro especialmente). Esse processo econômico no Leste Asiático é conhecido por "gansos voadores”, termo revitalizado por AKAMATSU (1962) não só para caracterizar essas décadas de 60 a 80, mas também o período durante o Império Japonês.

Contudo, essas mudanças na estrutura econômica implicaram também novos desafios para esses países. Internamente, eles sofreram pressões em prol da democratização, da melhoria das relações trabalhistas e também das condições sociais da população. Isto é, eles teriam de perder as supostas vantagens comparativas de serem regimes ditatoriais repressivos, assentados numa dinâmica de grande exploração da mão de obra local e no controle estatal sobre a economia e voltado para o mercado externo.

Então, a industrialização dos Tigres Asiáticos pode ser vista como uma forma de manutenção de "ilhas" capitalistas de prosperidade a fim de reforçar o cordão anticomunista no Leste Asiático e baratear o fornecimento de bens fundamentais para as indústrias das economias capitalistas desenvolvidas. Os quatro países mais o Japão permaneceram "protetorados militares e clientes políticos" dos EUA, 
que se especializava no suprimento de proteção político-militar, enquanto seus grupos dirigentes puderam se especializar na busca por lucro (ARRIGHI, 1997).

Além disso, outro impacto, mais sistêmico, foi o deslocamento do eixo dinâmico de acumulação capitalista do Atlântico para o Pacífico, mais especificamente para o Leste da Ásia. Os Tigres Asiáticos desempenharam papel fundamental nessa mudança após se consolidarem como plataformas de exportação, durante os anos 70 e 80 . No início desse período de intenso desenvolvimento, esses quatro pequenos países exportavam produtos de baixo valor agregado e componentes básicos para os países centrais nesse sistema. Todavia, com o passar do tempo, eles souberam se valer dos conhecimentos adquiridos (baseados na experiência japonesa) para se lançarem como atores dentro do mesmo sistema em que tinham posições inferiores e se tornarem novos polos irradiadores de capitais e de tecnologia. Por conseguinte, no alvorecer dos anos 90, os quatro Tigres alcançaram uma posição de desafiadores da liderança econômica japonesa na região.

\section{Os Tigres no Pós-Guerra Fria}

Os Tigres Asiáticos, já desde os anos 80, ao dar prosseguimento ao processo dos "gansos voadores" fortaleceu o desenvolvimento da República Popular da China, pois todos eles apresentavam forte presença de uma diáspora chinesa atuante na indústria (embora com menor peso na Coreia do Sul). Assim, pode-se dizer que os $\mathrm{Ti}^{-}$ gres incentivaram o surgimento de uma grande potência principalmente nos anos 90 . Hong Kong foi reincorporado ao território chinês 
em 1997, garantindo à RPC o controle direto de um dos principais portos e centros financeiros mundiais. Esse fato também simbolizou a chegada à condição de potência, bem como, juntamente com a reintegração de Macau em 1999, o fim do colonialismo no Leste Asiático. Entretanto, o processo de fortalecimento chinês na região deve ser também compreendido tendo em vista o Japão, que mergulhou numa estagnação econômica desde o início dos anos 1990 e não conseguia mais desempenhar o papel de grande e único polo fomentador dessa dinâmica econômica.

Não obstante, cada um dos Tigres adotou uma estratégia diferente para se adaptar a nova conjuntura internacional do Pós-Guerra Fria, em que o combate ao comunismo deixou de ser uma bandeira dos EUA. Hong Kong, apesar de manter leis próprias, após se reintegrar a China passou a desempenhar um papel central na estratégia de inserção chinesa na dinâmica comercial mundial, bem como na afirmação desse país como potência mundial. Taiwan também buscou uma integração maior com a RPC em termos econômicos ao longo da década de 1990 e, embora ainda se recuse a ser reincorporada ao continente, houve uma aproximação da elite econômica do país com os chineses da RPC. Cingapura, dada a sua localização, procurou se articular mais (econômica e politicamente) com os países do Sudeste Asiático, e a ASEAN constituiu-se na peça fundamental dessa estratégia. Por fim, a Coreia do Sul, às voltas ainda com a questão da reunificação da península coreana, apesar de ter sido o mais afetado dos Tigres pela crise de 1997, buscou se inserir no jogo das potências da região, aproximando-se da China e investindo cifras expressivas em gastos militares. Cabe 
ressaltar também que o país, a fim de aumentar a sua relevância no sistema regional e mundial, dinamizou os seus investimentos mundiais e viu alguns dos seus chaebols, conglomerados empresariais, se consolidarem como algumas das maiores empresas mundiais nos ramos em que atuam.

Além disso, cabe destacar o papel que a crise asiática de 1997 teve nessas economias, afetando-as com graus variados de intensidade, contudo sinalizando para estes países que uma maior integração com o restante do continente se fazia necessária em prol de manterem a posição de atores relevantes na economia regional, uma vez que os EUA não se mostraram muito dispostos a arcar com os custos de uma ajuda financeira a países então já desenvolvidos. A China, portanto, se mostrou também como um parceiro estratégico, bem como os países do Sudeste Asiático. Além disso, eles precisaram abrir ainda mais as suas economias para a entrada de capitais externos e estimular o desenvolvimento de outros ramos econômicos.

\section{Surgimento da ASEAN}

A ASEAN foi fundada por Indonésia, Malásia, Filipinas, Cingapura e Tailândia em 1967 em Bangcoc. Contudo, seus antecedentes advieram do Pós-2a Guerra Mundial e do processo de descolonização. Com a derrota do Império do Japão e a decadência dos antigos Impérios Ocidentais, surgiu uma série de novos estados independentes na Ásia Oriental, estados débeis marcados por problemas socioeconômicos e clivagens étnicas. Estas "imitações de estados" buscavam desesperadamente por uma forma de se legitimar interna- 
mente, mas principalmente por um meio de legitimação perante o Sistema Internacional (JONES \& SMITH, 2006, p. 44).

A dinâmica da Guerra Fria trouxe a oportunidade para esta legitimação. Primeiro, através da Conferência de Bandung em 1955 e a tentativa de estabelecer uma posição neutra para as ex-colônias. Em segundo lugar, para fins de legitimação interna, adotaram-se práticas paternalistas que procuravam tornar o povo coeso acerca de objetivos econômicos. Esse foi o caminho adotado pelos cinco países fundadores da ASEAN.

Entretanto, os interesses estratégicos estadunidenses, a Segunda Guerra da Indochina e a penetração dos capitais japoneses via processo de subcontratação não permitiram a manutenção desta posição "não-alinhada". Desta forma, após a Konfrontasi ${ }^{1}$, Sukarno é deposto com auxílio da CIA (VIZENTINI \& RODRIGUES, 2000, p. 35-36), assumindo Suharto em 1965 que redefiniu a relação dos EUA com a Indonésia, Estado pino do Sudeste Asiático. Esse foi o pontapé inicial que levou à formação da ASEAN em 1967.

Sendo assim, a ASEAN surge como um bloco antissoviético, principalmente como forma de contenção da "ameaça vietnamita", aliado da URSS. Porém, o anúncio da Doutrina Nixon em julho de 1969 em Guam, que afirma que os aliados estadunidenses devem cuidar de sua própria defesa, acaba incentivando a regionalização em todo o mundo, e com a ASEAN não foi diferente. Agora a vaga aliança contra o comunismo era responsável por garantir a paz, a estabili-

1 Konfrontasi (1962-1966): Guerra não declarada entre Malásia e Indonésia pelo controle da ilha de Bornéu. 
dade na região e suas independências.

Assim, a ASEAN acaba se tornando um dos protagonistas da região, o que leva os estados deste bloco a mais uma vez tentar garantir sua independência de potências externas. Desta forma, surge em 1971, por iniciativa dos membros da ASEAN, a zona de paz, liberdade e neutralidade do sudeste asiático ou ZOPFAN. A ZOPFAN foi uma tentativa de criar uma política externa independente para os países membros da ASEAN, mas na prática apenas corroborou o seu alinhamento com a China (RPC) e os EUA. Este alinhamento pode ser verificado pelo papel que a ASEAN desempenhou na questão da ocupação vietnamita do Camboja. Os membros da ASEAN foram contra o reconhecimento do governo da nova República Popular de Kampuchea, que substituiu o regime do Khmer Vermelho, promoveram a organização de um governo em exílio, que contou com a participação de Pol Pot apesar dos já conhecidos crimes contra a humanidade perpetrados durante seu governo, e viabilizaram o reconhecimento deste governo como o verdadeiro representante do Camboja pela ONU em 1982.

Apesar da aparente eficiência e pró-atividade da ASEAN nessa questão, isso só deu resultado, porque coincidiu com os interesses sino-americanos (JONES \& SMITH, 2006, p. 55). Assim, constatamos que a ASEAN, durante a Guerra Fria, é um bloco unido por uma ideologia antissoviética relevante para a manutenção da independência e integralidade territorial dos estados membros, mas que, por suas debilidades, são forçados a praticar bandwagoning com relação aos EUA e à RPC. Porém, a partir da década de 1990, ocorre um aumento da institucionalização deste bloco, alterando esse perfil. 
InterAção | 135

\section{A Institucionalização do Sudeste Asiático}

O contexto do final da década de 1980 proveu à ASEAN a oportunidade de cumprir seu objetivo de representar a totalidade dos países da região. A partir de 1989, a retração internacional da URSS teve como consequência imediata o fim do suporte estratégico fornecido ao seu aliado na Indochina, o Vietnã. Com tal virada conjuntural, o Vietnã começa a retirar sua presença militar do Camboja, que permanece em um quadro de guerra civil até o estabelecimento da administração da força de manutenção da paz das Nações Unidas através das decisões da Conferência de Paris.

Com o fim da ação desestabilizadora do Vietnã, a primeira metade da década de 1990 contou com uma série de iniciativas em prol da institucionalização do regionalismo, dentre as quais se destacam a criação da Área de Livre Comércio da ASEAN (ASEANFTA) em 1992, do Fórum Regional da ASEAN (ARF) em 1994 e, fechando simbolicamente o ciclo, a adesão do Vietnã à organização em 1995. A entrada do Vietnã se explica pela percepção generalizada de que a ASEAN como instituição se confirmaria como um centro de decisão independente da cada vez maior influência chinesa (ABAD JR, 2003).

Sob o ponto de vista regional, o fim das ocupações militares e o exemplo de desempenho econômico dado principalmente por Cingapura transformam substancialmente a dinâmica local. Usando os termos de BUZAN \& WAEVER (2003), a região passa de um estado de formação de conflitos para um arranjo securitário. Isto é, embora o uso de violência em litígios interestatais não seja completamente 
descartado, como na instituição de uma comunidade aos moldes europeus, a estrutura regional favorece resoluções pacíficas. A principal moeda de poder é então o desempenho econômico pela consequente legitimação que traria para os governos frente o povo, fim que pode ser mais facilmente atingido através da cooperação.

A percepção do sucesso da "ASEAN Way" se verificou com a rápida consolidação do projeto de criar um arranjo político pan-asiático através do Fórum Regional. O Fórum conta com a participação de todos os atores relevantes para a segurança regional do Leste e Sul Asiáticos, assim representando a tentativa de exportar o modelo de normas e princípios diplomáticos mesmo para as grandes potências regionais. Mais importante, percebe-se a tentativa de cooptar a política externa chinesa para os princípios de soberania e não-intervenção cristalizados no Tratado de Amizade e Cooperação de 1976 (BEUKEL, 2008).

O período dourado do padrão de abordagem diplomática apresentado se encerra em 1997 com a crise asiática. A crise econômica, que se iniciou na Tailândia e rapidamente contagiou as economias vizinhas, afetou negativamente a reputação do projeto de desenvolvimento econômico baseado na cooperação regional. Assim, a crise também teve efeitos na esfera doméstica, revertendo o processo da primeira metade da década e enfraquecendo a imagem dos governos associados ao período anterior. É representativa a queda do regime de Suharto na Indonésia em 1998, que consolidou uma onda de fortalecimento da democracia no Sudeste Asiático.

Ainda em 1997, a primeira reunião do grupo ASEAN+3 marcou a nova realidade: de forma a preservar os ganhos institucionais, 
a organização se associou, ao mesmo tempo, às três grandes maiores economias do Leste Asiático: Japão, RPC e Coreia do Sul. O evento demarca o fim da primazia absoluta do modelo ASEAN+1, isto é, em que o bloco sempre negociava em conjunto com uma parte por vez. A crise asiática também selou a amálgama entre o Sudeste e o Leste Asiáticos, que apresentaram sintonia muito superior à destes com o Sul, apesar da "Look East Policy" promovida pela Índia.

Após a crise, a ASEAN perdeu relativamente seu papel como ator internacional, dando espaço para a diversificação das ações individuais dos seus Estados-membros. No contexto do jogo com as potências extrarregionais, as respostas também se diversificaram: Malásia e Vietnã firmaram acordos militares com a Rússia; Indonésia se aproximou do Japão e hoje ensaia uma parceria com a Coreia do Sul, entre outros.

A mescla econômica entre Sudeste e Leste também assumiu outra forma após a crise. Com a confirmação da lenta queda da economia japonesa, o modelo dos "gansos voadores" deu lugar à fragmentação da rede produtiva. $\mathrm{O}$ fim da liderança do modelo japonês não significou necessariamente o surgimento de uma liderança análoga na RPC, e sim em uma mudança na relação entre as três grandes economias e os países emergentes do Sudeste. Embora o peso do investimento direto chinês, por exemplo, ultrapasse os 50\% no seu antigo adversário, o Vietnã, a ação de empresas multinacionais japonesas e coreanas diversificam as opções e conferem algum grau de escolha aos países da ASEAN (HAMAGUCHI, 2008).

Ultimamente, dois novos fatores têm pesado na dinâmica dos países do Sudeste asiático com as potências extrarregionais. O pri- 
meiro é a ascensão indiana e a maturação do projeto de aproximação econômica com o Leste. $\mathrm{Na}$ medida em que a China começa a atuar no Oceano Índico, a Índia investe nas relações com possíveis parceiros na ASEAN por motivos econômicos e securitários, principalmente através dos Acordos Globais de Cooperação Econômica², que, em comparação com o quadro dos acordos de livre comércio da ASEAN, possuem uma pauta de produtos e serviços muito mais abrangente. O segundo fator é a influência latente das normas e princípios da ASEAN, mesmo em um contexto regional que contempla a participação de grandes potências. Isto é, as instituições regionais criadas no começo da década de 1990, como a Cúpula do Leste Asiático e o ARF, ainda são os principais fóruns multilaterais nos temas que condizem à região da Ásia-Pacífico, muito embora não sejam dotadas de quaisquer formas de assegurar as suas decisões. Qualquer mudança neste aspecto teria consequências drásticas para a dinâmica regional.

\section{CONSIDERAÇÕES FINAIS}

Os países emergentes da Ásia-Pacífico, desde seu surgimento como Estados-nação no pós-2a Guerra Mundial, sempre tiveram que lidar com as ambições e a influência de grandes potências, sejam elas regionais ou globais. Tanto os países da ASEAN como os Tigres Asiáticos procuraram sempre evitar a supremacia de uma só potência, sendo que o ator mais influente em dada região molda a atuação do país de forma antagônica. Assim, Coreia do Sul e Taiwan aderiram

2 Tradução livre de "Comprehensive Economic Cooperation Agreement". 
completamente à retórica anticomunista pela ameaça de anexação por países socialistas; o Vietnã, enquanto a maior ameaça era um Sul que contava com o apoio estadunidense, contou com o apoio chinês - assim que este perigo se dissipou, reacenderam as tensões étnicas históricas entre vietnamitas e chineses. Cingapura, que após sua expulsão da Federação Malaia contava com uma economia irrisória e com ameaça urgente tanto através da Malásia quanto da Indonésia, estabeleceu um programa de desenvolvimento que cooptou investimentos ao mesmo tempo em que resguardava alto grau de independência dos importados da região através do fomento à indústria. Enquanto os outros casos confirmam a lógica, a exceção ao argumento é Hong Kong, que, embora com uma economia representativa, nunca teve expressão política considerável.

Em suma, podemos observar que desde os anos 70, com a nascente interdependência econômica entre eles, o regionalismo se fortaleceu e os EUA, com a Doutrina Nixon, perderam espaço para a RPC e para o Japão, ou até mesmo para Coreia do Sul, Taiwan e Cingapura (SHAMBAUGH \& YAHUDA, 2008). Dos anos 70 aos 90, então, verifica-se que tanto os países da ASEAN quanto os Tigres souberam jogar com os interesses dos "gigantes" para poderem caminhar livremente, ou seja, conseguiram barganhar ante as potências para crescer economicamente, promover o desenvolvimento e manter sua autonomia. Entretanto, cabe ressaltar que não foi somente a atuação dos "gigantes" que figuram no topo da agenda dos países emergentes do Leste Asiático. Mesmo durante a década de 1970, a agenda da ASEAN já contemplava os perigos do desequilíbrio na Indochina com o expansionismo vietnamita nos vizinhos Laos e Camboja. 
140 | InterAção

Portanto, a questão que provavelmente moldará a dinâmica regional nos próximos anos é o quanto os países aqui estudados estão agindo contra a consolidação da hegemonia da RPC. Fica claro também que, enquanto se mantiver a ameaça de subordinação econômica a Pequim e quanto mais agressivo for o comportamento internacional sínico, maior importância será dada à participação estadunidense no Leste Asiático. Além disso, a ASEAN como organização figuraria como um dos pilares de um mundo multipolarizado sem enfrentamento direto com os interesses estadunidenses. Países como a Rússia e a Índia ainda não possuem força nem influência na região a ponto de alterar o quadro de alianças no Sudeste Asiático. Embora a Rússia figure como fonte de aparato militar, ela ainda não consegue prover parcerias estratégicas na profundidade das oferecidas pelos EUA. No que tange a Índia, apesar de ainda desempenhar uma presença modesta quando comparada com os demais atores, o país possivelmente tenderá a participar ativamente dos assuntos da região: a economia da ASEAN em conjunto já tem peso no comércio indiano quase em paridade com o da RPC.

Contudo, apesar da ascensão da RPC, os países apresentados continuarão procurando meios de conciliar os benefícios dos investimentos chineses com a manutenção da soberania nacional. $\mathrm{O}$ quadro apresentado, então, indica que a tendência é a manutenção da autonomia, do mesmo modo que já foi realizado entre as décadas de 70 e 90.

\section{REFERÊNCIAS}

ABAD JR, M.C.. The Association of Southeast Asian Nations: 
Challenges and Responses. In: WESLEY, Michael. The Regional Organizations of the Asia-Pacific. Nova Iorque: Palgrave Macmillan, 2003. p. 40-59.

AKAMATSU, K. "A historical pattern of economic growth in developing countries”. In: Journal of Developing Economies, 1(1):325, Março-Agosto 1962.

ARRIGHI, Giovanni. A ilusão do desenvolvimento. Petrópolis: Ed. Vozes, 1997.

BEUKEL, Erik. ASEAN and ARF In East Asia's Security

Architecture: The Role of Norms and Powers. Copenhague: Danish Institute For International Studies, 2008.

BUZAN, Barry; WAEVER, Ole. Regions and Powers. Nova Iorque: Cambridge University Press, 2003.

JONES, Dave Martin; SMITH, M.L.R. ASEAN and East Asian relations: Regional delusion. Cheltenham: Edward Elgar Publishing, 2006.

HAMAGUCHI, Nobuaki. Fragmentation and Production Network in East Asia. Kobe Economic \& Business Review, Kobe, v. 1, n. 52, p.726, fev. 2008.

SHAMBAUGH, David; YAHUDA, Michael. International Relations of Asia. Nova Iorque: Rowman \& Littlefield Publishers, 2008.

VIZENTINI, Paulo Fagundes; RODRIGUES, Gabriela. O Dragão Chinês e os Tigres Asiáticos. Porto Alegre: Novo Século, 2000. 
142 | InterAção 